\title{
Schistosomiasis mansoni incidence data in Rwanda can improve prevalence assessments, by providing high-resolution hotspot and risk factors identification
}

\author{
E. Nyandwi ${ }^{1,2^{*}}$, A. Veldkamp ${ }^{1}$, S. Amer ${ }^{1}$, C. Karema $^{4,5}$ and I. Umulisa ${ }^{3}$
}

\begin{abstract}
Background: Schistosomiasis mansoni constitutes a significant public health problem in Rwanda. The nationwide prevalence mapping conducted in 2007-2008 revealed that prevalence per district ranges from 0 to $69.5 \%$ among school children. In response, mass drug administration campaigns were initiated. However, a few years later some additional small-scale studies revealed the existence of areas of high transmission in districts formerly classified as low endemic suggesting the need for a more accurate methodology for identification of hotspots. This study investigated if confirmed cases of schistosomiasis recorded at health facility level can be used to, next to existing prevalence data, detect geographically more accurate hotspots of the disease and its associated risk factors.
\end{abstract}

Methods: A GIS-based spatial and statistical analysis was carried out. Confirmed cases, recorded at primary health facilities level, were combined with demographic data to calculate incidence rates for each of 367 health facility service area. Empirical Bayesian smoothing was used to deal with rate instability. Incidence rates were compared with prevalence data to identify their level of agreement. Spatial autocorrelation of the incidence rates was analyzed using Moran's Index, to check if spatial clustering occurs. Finally, the spatial relationship between schistosomiasis distribution and potential risk factors was assessed using multiple regression.

Results: Incidence rates for 2007-2008 were highly correlated with prevalence values $\left(R^{2}=0.79\right)$, indicating that in the case of Rwanda incidence data can be used as a proxy for prevalence data. We observed a focal distribution of schistosomiasis with a significant spatial autocorrelation (Moran's $/>0: 0,05-0.20$ and $p \leq 0,05$ ), indicating the occurrence of hotspots. Regarding risk factors, it was identified that the spatial pattern of schistosomiasis is significantly associated with wetland conditions and rice cultivation.

Conclusion: In Rwanda the high density of health facilities and the standardized microscopic laboratory diagnostic allow the derived data to be used to complement prevalence studies to identify hotspots of schistosomiasis and its associated risk factors. This type of information, in turn, can support disease control interventions and monitoring.

Keywords: Schistosomiasis mansoni, Incidence rates, Risk factors, Spatial scale, Empirical model

\footnotetext{
*Correspondence: e.nyandwi@utwente.nl; nyasept@gmail.com

${ }^{1}$ Faculty of Geo-Information Science and Earth Observation (ITC), University

of Twente, P. O. Box 217, 7500 AE Enschede, the Netherlands

${ }^{2}$ Geographic Information Systems and Remote Sensing Centre of University

of Rwanda, P.O Box 212, Huye, Rwanda

Full list of author information is available at the end of the article
} 


\section{Background}

Schistosomiasis remains one of the most prevalent waterbased diseases in the tropics. Regarding the impact, it is considered the second most important parasitic disease after malaria in many countries in sub-Saharan Africa $[1,2]$. In Rwanda, schistosomiasis mansoni, (written as "S. mansoni" in this paper) with district level prevalence ranging from 0 to as much as $69.5 \%$ among school children constitutes a significant public health problem. The overall country prevalence in 2007-2008 was $2.7 \%$.

The Neglected Tropical Disease (NTD) control program was established in 2007 by the Ministry of Health to fight against five NTDs which pose a significant public health problem. This program included the Schistosomiasis Control Initiative, which was implemented using the nationwide school-based prevalence map of 2007-2008 as a guideline. The prevalence recorded at 2 to 4 surveyed schools per district was averaged to estimate prevalence at the district level (nationwide 136 schools were surveyed). The Mass Drug Administration (MDA) for S. mansoni targeted children in areas with a prevalence of at least $10 \%$ and included adults where prevalence exceeded 30\% [3].

However, two years later, some health facility located in districts classified as having a low prevalence, recorded higher frequencies of $S$. mansoni infection. In addition, some small-scale prevalence surveys revealed the existence of localized geographic areas with higher prevalence (up to $77.9 \%$ ) than previously reported $[4,5]$. One such study identified a 'new' area with the high rates of schistosomiasis [6], which was not detected before by the national prevalence study. The latter confirms the general recommendation of prevalence based studies in Rwanda or elsewhere in Africa [7, 8] that more detailed information is required to address the often highly focalized spatial pattern of schistosomiasis hotspots. The same studies also recommend to include other high-risk community groups (e.g.: women of children bearing age, rice farmers, fisherman) in future investigations.

To achieve this, the nationwide school-based prevalence surveys would need to include a very large number of schools and other high-risk community groups to provide sufficient information to identify and delineate hotspots. In Rwanda, districts are relatively large administrative units (see Fig. 1a). To overcome the low granularity of the current mapping method [9], the prevalence surveys would require large numbers of sample locations and becomes very expensive and harder to execute. Consequently, there is a clear need to explore the value of other sources of health data and alternative mapping approaches to complement prevalence inventories and support planning and implementation of $S$. mansoni control programs. For other water based diseases, incidence data from routine health statistics have been successfully used to complement prevalence studies and identify the spatial distribution of a given disease [10-12]. Given the availability of good quality spatially structured and systematically collected data at the health facility level, use of such incidence data seems feasible in Rwanda.

Since incidence and prevalence have a direct relationship (prevalence $=$ incidence rate $\mathrm{x}$ average duration of disease), a logical first step is to explore to what extent both have a similar spatial distribution. If there is a significant level of the agreement, it can be useful to use the much higher resolution incidence data for improved mapping of hotspots, and so more efficiently guide control interventions to high-risk locations.

From previous studies, it is known that the transmission of $S$. mansoni follows complex pathways depending strongly on the dynamics of the local biophysical and socio-economic context. Socio-economic and biophysical factors together influence when and where humans are in contact with water potentially contaminated with freshwater snails [13]. In the Rwandan situation, new infrastructural developments such as dams and irrigation scheme expansion could very well contribute to the spread of $S$. mansoni to previously non-endemic areas [14]. The association with irrigation projects is well scrutinized by Steinmann et al. [15] in a systematic review of the relation between schistosomiasis occurrence and irrigated areas in some African countries. Specific socioeconomic conditions such as educational attainment, access to improved water sources, and proper sanitation, are also known to be related to $S$. mansoni infection in endemic areas $[16,17]$.

This study aims to investigate if schistosomiasis incidence data recorded at health facility level can provide, next to existing prevalence data, additional insights into the spatial pattern of schistosomiasis occurrence. Given the fine-grained spatial resolution of health facility service areas in Rwanda, this could allow more detailed spatial hotspot detection of the disease and its associated risk factors.

\section{Methods}

Study area

Rwanda is a relatively small landlocked country of $26,338 \mathrm{~km}^{2}$ in the Great Lakes region of CentralEastern Africa with a climate characterized by two rainy and two dry seasons. Administratively, Rwanda is divided into five provinces, 30 districts and 416 sectors [18]. The sectors together make up 367 health facility service areas (HFSAs), as shown in Fig. 1b. Around 11 million people inhabit the country [19], of which $83.5 \%$ live in the countryside mainly engaged in small-scale farming. Because of shortages of agricultural land, wetland conversion is one of the ongoing activities for rural development [20]. 


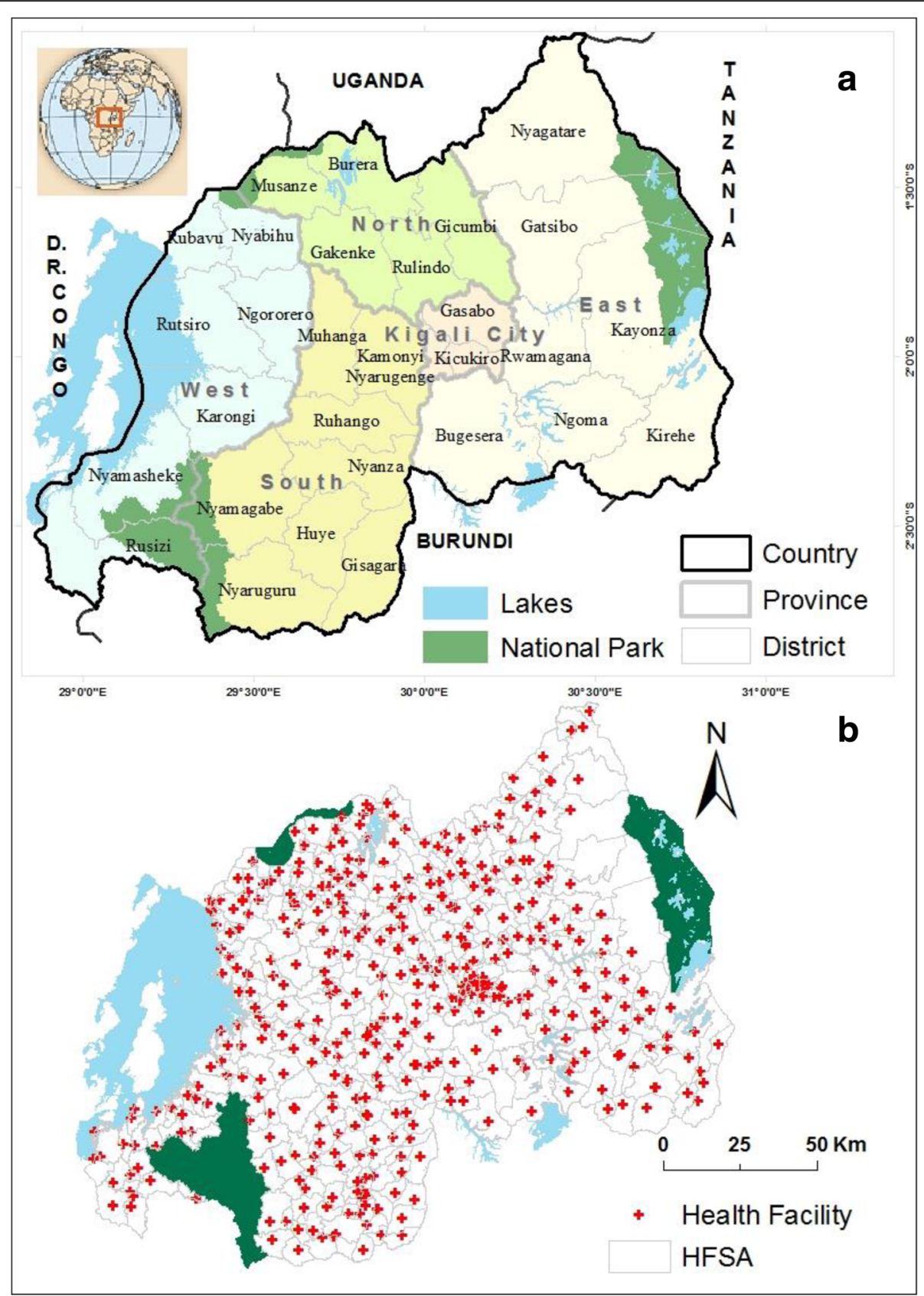

Fig. 1 Map of Rwanda. The 30 administrative districts with Province boundary shown in different colors (a) Primary health facility (HF) location with their respective service area (HFSA) boundary (b). There are few health facilities in a strip of relatively larger HFSAs in East of the country recently and lowly populated by cattle farmers settled in grouped settlement far from National park boundary and former hunting domain

Over time, Rwanda's health sector has experienced a profound evolution from traditional healing methods to faith-based health care during the colonial period, then centralized, and free provision of health services up to the early 1990's, to the current decentralized health care delivery system. The decentralization reinforces community participation in the management and financing of health services. The current public health care delivery system is a hierarchically organized three-tier system providing primary, secondary and tertiary health care. Primary health care is provided at sector level via one or more health facilities, secondary care is provided in the districts by a district hospital, and referral hospitals provide tertiary care at the regional scale. Each health facility reports to the district health office, which is responsible for the health facilities and services provided to the population of the district. Community Health Workers (CHWs)function as an effective link 
between communities and public health care initiatives (Health Policy of Ministry of Health elaborated in 2005).

\section{Data collection and quality checking Administrative boundaries and spatial delineation of health facility service areas}

The geographic location of health facilities depicting the 2007 situation, were provided by the Rwanda Biomedical Centre - Malaria and Other Parasitic Diseases Division (RBC/M\&OPD). For this study, the health facility data were updated in May-June 2013 via intensive consultation of District Land Officers, Surveyors, and GIS Technicians from each administrative district. Furthermore, we spatially demarcated the HFSA using the 'cost allocation' spatial analyst tool of ArcGIS. Then, the delineated areas were further adjusted to the administrative units considering the population size, physical and managerial boundary as planned for Community-Based Health Insurances (CBHI) scheme management (In Ministerial Instruction Nr /Min/2012 on District - Health -Guidelines, 2012). The administrative boundaries of the country at different levels were obtained from the National Institute of Statistics of Rwanda. The general information data sets such as lakes, islands, parks, and roads, have been acquired from the Centre for GIS and Remote Sensing of the University of Rwanda (CGIS-UR).

\section{Schistosomiasis mansoni incidence data}

The number of confirmed cases of $S$. mansoni for the years 2007-2012 were provided for this study by the RBC/ M\&OPD. The same department also provided point locations and prevalence data obtained at the schools included in the nationwide school-based prevalence survey of 2007-2008. Another prevalence map produced using supra-national data, and regional simulation was also available from the World Health Organization [21]. The quality of recorded schistosomiasis infection cases at HFSA level is sound for six reasons. First, S. mansoni infection is diagnosed via microscopic identification of eggs in stool samples in the laboratory of the health facility. Second, accessibility is unproblematic as patients can reach a health facility within a walking distance of at most $5 \mathrm{~km}$. Third, Community-Based Health Insurance (CBHI) makes that appropriate health care is affordable for everyone (patients pay only $10 \%$ of the total cost of service and medication). Fourth, community health workers actively stimulate patients to visit the health facility in case of suspected health problems. Fifth, since there is no traditional medicine used for Schistosomiasis in Rwanda, patients with symptoms will go for treatment at the health facility. Sixth, the Rwandan Health Management Information System (R-HMIS), routinely and systematically collects health records from individual health facilities using a web-based software platform (DHIS2) whereby each health facility enters their monthly health records directly into the national database [22].

\section{Socio-economic and biophysical covariates}

Demographic data were extracted from the 2002 and 2012 Population, and Housing Census published by the National Institute of Statistics of Rwanda (NISR) and for the years in between the estimated population number and distribution were extracted from estimation and projections also reported by NISR. The socio-economic factors such as school attendance levels, access to improved water sources, proper sanitation at district and HFSA level were available from census reports.

S. mansoni transmission is determined and accelerated by interactions of various factors spatially restricted to freshwater bodies inhabited by particular host snails [23]. Earlier studies in East African countries identified numerous biophysical and socio-economic conditions related to schistosomiasis infection risk [1]. In addition to socio-economic factors, biophysical factors need to be considered as well. Wetland agro-ecosystems related factors (namely wetland proportion, rice cropped areas, wetland/water body adjacency) were also collected. Likewise, topographic and climatic factors were used as potential risk factors for this study. Data acquisition and pre-processing methods to generate raster data for the risk factors are detailed in previous research on Rwandan wetlands characterization and their climate sensitivity [24]. Soil parameters $(\mathrm{pH}$, clay, and sand content percentage) were extracted from the soil geo-database of Rwanda generated from a semi-detailed soil survey consisting of 1833 soil profiles spread over the country. The geostatistical interpolation of soil properties was done using landform data at a scale of 1: 250,000 and 1: 50,000 [25]. Mean values at HFSA level were extracted from original risk factors raster data using zonal statistics tools of ArcGIS 10.2.2. District factor values are the average of values of HFSAs within a district.

\section{Comparison of spatial distribution of S. mansoni with incidence and prevalence datasets}

Incidence and prevalence are both measurements of disease frequency. Incidence estimates how often disease occurs in space and time (a measure of disease risk). Prevalence evaluates how much the disease is spread in a given population (a measure of disease burden) at a given moment. Since both are related (prevalence $=$ incidence rates $\mathrm{x}$ average duration of disease), high prevalence areas may correspond with high incidence rates for a disease such as $S$. mansoni. The 2008 prevalence at each of the 136 surveyed schools is directly compared with incidence rates at HFSA level for the same year and location. Prevalence and incidence data were also mapped at the district level to enable visual comparison. 


\section{Detection and visualization of the spatial pattern of $S$. mansoni}

Appropriate spatial and statistical approaches for detecting spatial clustering and relationships with risk factors are provided by current advances in spatial epidemiology $[26,27]$.

\section{Cases of S. mansoni per population at risk}

The number of confirmed cases of $S$. mansoni per HFSA per month were summed per year and further aggregated to the district level. The generated annual S. mansoni incidence cases and demographic data were joined using Excel and then linked to the HFSA and district spatial data. The incidence rate is the number of $S$. mansoni cases per district $(n=30)$ or HFSA $(n=367)$ divided by the population of that district or HFSA, as shown by the equation below:

$$
\mathrm{Di}=(\mathrm{In} / \mathrm{Pt}) * 100000
$$

Where $\boldsymbol{D} \boldsymbol{i}$ is the $S$. mansoni incidence rate, $\boldsymbol{I n}$ is the total number of new cases in 12 months of a year per district/HCSA, and $\boldsymbol{P t}$ is the total population of that year for that entity.

To make the rates more intuitive, they were multiplied by 100,000 to obtain incidence rates reported per one hundred thousand persons [28]. The raw rates from sparsely populated HFSAs were replaced by weighted averages using Empirical Bayesian Smoothing (EBS) [29]. EBS computes raw rates and produces three weighted rates using the global, mean and local average. The smoothing was done using the SpaceStat software [30].

For visualization, incidence rates were classified into four classes using the Jenks classification. The classes defined in this way were harmonized to allow for interannual comparison and comparison with prevalence maps at the district level. Furthermore, the average incidence rates for 2007 and 2008 at HFSA level were standardized to vary from 0 to 1 (from non-endemic to hyperendemic areas) and superimposed with the points map of the 136 schools surveyed during the nationwide mapping of 2007-2008. A scatterplot was then generated to display the relationship between incidence rates at HFSA level and prevalence per school.

\section{Analyzing pattern with Moran's index statistic}

Spatial autocorrelation was computed to ascertain the correlation between neighboring incidence rates of $S$. mansoni and the level of spatial clustering within the study area [31]. The Moran's Index statistic, similar to the Pearson correlation [32], is widely used for this and was calculated as:

$$
I=\frac{N}{S_{O}} \sum_{i} \sum_{j} w_{i j} \frac{\left(x_{i}-u\right)\left(x_{j}-u\right)}{\sum_{i}\left(x_{i}-u\right)^{2}},
$$

Where $N$ is the number of districts/HFSA; $\boldsymbol{W}_{\boldsymbol{i}}$ is the element in the spatial weights matrix corresponding to the observation pair $\boldsymbol{i}, \boldsymbol{j}$. Also, $\boldsymbol{x}_{\boldsymbol{i}}$ and $\boldsymbol{j}_{\boldsymbol{i}}$ are observation for areas $\boldsymbol{i}$ and $\boldsymbol{j}$ with mean $\boldsymbol{u}$. And

$$
S_{O}=\sum_{i} \sum_{j} w_{i j}
$$

Since the weights are row-standardized $\sum \boldsymbol{w}_{i j}=1$, the first step in the spatial autocorrelation analysis is to construct a spatial weight matrix that contains information about the neighborhood structure for each location. Adjacency is defined as the immediately neighboring district/HFSA, including the district/HFSA itself [33]. Non-neighboring units have a weight of zero.

\section{Mapping clusters}

The Local $G_{i}^{*}(d)$ statistic was selected to test the statistical significance of local clusters and to determine the spatial extent of these clusters $[34,35]$. The Local $G_{i}{ }^{*}(d)$ statistic is useful for identifying individual members of local clusters by determining the spatial dependence and neighboring observations $[26,36]$. It can be written as follows:

$$
G_{i}^{*}(d)=\frac{\sum_{j} w_{i j}(d) x_{j}-W_{i} \bar{x}}{s \sqrt{\frac{\left(n S_{1 i}-W_{i}^{2}\right)}{(n-1)}}}, \text { for all } j
$$

Where $x$ is a measure of incidence rate of $S$. mansoni within a given district/HFSA polygon; $W_{i j}$ is a spatial weight that defines neighboring district/HFSA $j$ to $i$; $W_{i}$ is the sum of the weight $W_{i j}$,

$$
\bar{x}=\frac{1}{n} \sum_{j} x_{j} \quad s_{1 i}=\sum_{j} w_{i j}^{2}, \quad s^{2}=\frac{1}{n} \sum_{j} x_{j}^{2}-\bar{x}^{2} .
$$

Developing the spatial weight $W_{i j}$ is the first step to calculating $G i^{*}(\mathrm{~d})$. The spatial weight matrix includes $W_{i j}=1$. and in this study, the adjacency has been defined in ArcGIS - proximity analysis based on polygons that share common boundaries and vertices [37].

With Local $G_{i}^{*}(d)$ statistic clusters with a $95 \%$ significance level from a two-tailed normal distribution indicate significant spatial clustering, but only positively significant clusters are mapped.

\section{Empirical modeling of S. mansoni with potentially associated factors}

Input data sets were standardized and prepared at HFSA level using standard functionality of ArcGIS. The attributes of the spatial data were exported to IBM SPSS Statistics, version 20 which was used for all statistical 
analyses. Before the use of the variables to train an exploratory empirical model, exploratory data analysis was done. Considering the patterns of data distribution, using normal distribution curves and frequency distributions; a log-normal distribution transformation was done for some of the input datasets [38]. Then, with normally and $\ln$-transformed variables, Pearson's rank correlation coefficient and the test of co-linearity using pairwise scatter plots was done. Sixty percent of the data was randomly sampled for the model, to avoid the spatial autocorrelation in our empirical regression and to prevent a fixed spatial pattern. With the spatial autocorrelation, the model becomes insensitive to changes in the spatial patterns and over fitted.

The incidence of $S$. mansoni, as the dependent variable, was related to all potential risk factors. Risk factors used in the statistical analysis were grouped into five. The first group is made up of physical variables, subcategorized as soil properties $(\mathrm{pH}$, sand percentage, and clay percentage) and terrain derivatives (elevation, slope, and terrain shape index). The second group represents ecological variables (wetland proportion, the total area of rice cropping schemes, water/lake adjacency). The third group consists of two climatic variables (total annual amount of rainfall and average annual temperature). The fourth group consists of four demographic variables (number of households, population density, and percentage of rural and urban residents). The last group represents socio-hygienic conditions, namely: level of education, the source of water and sanitation situation.

A stepwise linear regression was conducted, considering $P>0.1$ as the removal criterion and $P \leq 0.05$ as the entry criterion. This quantifies the strength of the relationship between schistosomiasis cases and the significant covariate(s). The standardized coefficients were used to compare the effects of each independent variable on the dependent variable [39]. To determine how well the regression model fitted the data, we used the R-square and the Standard Errors of the Regression (S). We considered the $\mathrm{S}$ to represent the average distance that the observed values deviate from the regression line. The $\mathrm{S}$ must be $\leq 2.5$ to produce a sufficiently narrow $95 \%$ prediction interval [40]. Also, we used both residuals and residual plots to analyze drift and variance of the values [41], for evaluating the appropriateness of the model.

\section{Results}

\section{Comparing prevalence and incidence data}

To check if indeed there is a significant relationship between prevalence and incidence data, we compared standardized incidence rates of 2007-2008 at HFSA level with prevalence data obtained at the 136 school sampled during the 2007-2008 nationwide survey. In Fig. 2, we can observe a very strong relationship between the two data sources with a coefficient of determination of 0.79 .

This strong relationship indicates that we can use routinely recorded cases of $S$. mansoni at primary health facility level to supplement prevalence data. The readily available incidence rates can be utilized as a proxy for prevalence. This information can be sourced on a monthly basis for every health facility for more than one decade.

\section{Spatial distribution of S. mansoni in Rwanda}

A total number of 1221 S. mansoni cases were reported in Rwanda for the years of 2007 and 2008. Annual incidence rates for 30 districts were calculated (Table 1). Nyagatare district had the highest rate of 57 cases per 100,000 persons in 2008. Then EBS incidence rates for 367 HFSAs were also calculated for the year 2007 and 2008. As visualized in Fig. 3, a lot of HFSAs, as well as

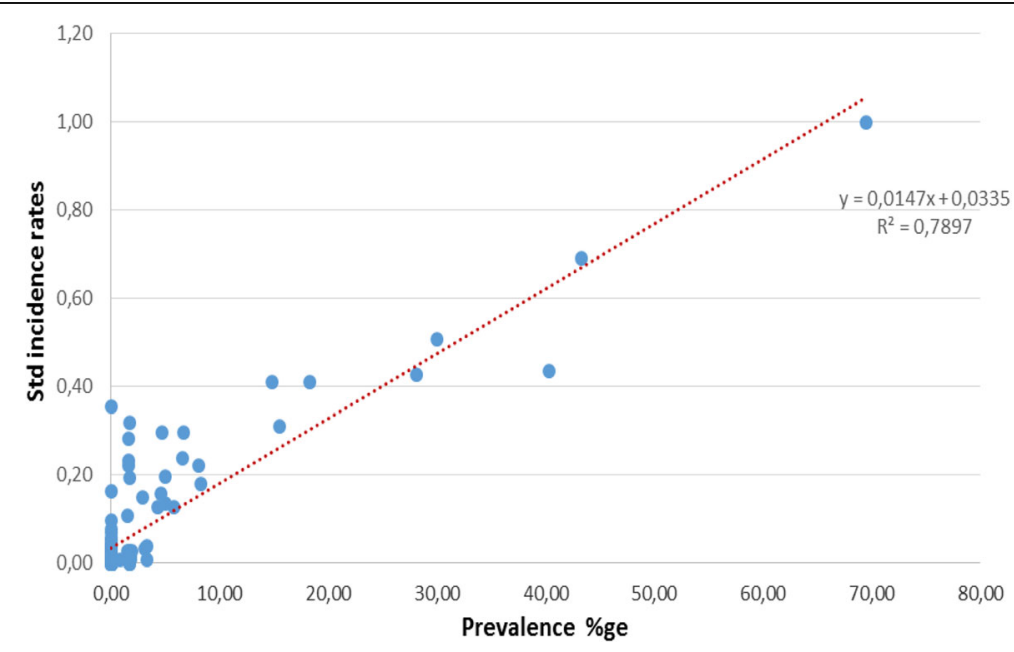

Fig. 2 Scatter plot and trend line between Prevalence and Incidence values. The prevalence proportion measured at each of 136 surveyed schools linked to their location; and corresponding standardized incidence rates were extracted for the same places 
Table 1 Incidence rates (per 100.000 persons) of S. mansoni in Rwanda for specific years (2007, 2008 and cumulative incidence (2007-2008)

\begin{tabular}{|c|c|c|c|}
\hline \multirow[t]{2}{*}{ District Name } & \multicolumn{3}{|l|}{ Year } \\
\hline & 2007 & 2008 & 2007-2008 \\
\hline Nyarugenge & 2,33 & 2,67 & 3,82 \\
\hline Gasabo & 5,39 & 6,42 & 8,40 \\
\hline Kicukiro & 0,41 & 1,17 & 0,78 \\
\hline Nyanza & 0,38 & 7,05 & 3,71 \\
\hline Gisagara & 1,05 & 1,37 & 1,72 \\
\hline Nyaruguru & 0,39 & 1,51 & 1,34 \\
\hline Huye & 0 & 11,43 & 5,71 \\
\hline Nyamagabe & 0 & 0,64 & 0,32 \\
\hline Ruhango & 0,72 & 0 & 0,71 \\
\hline Muhanga & 0,66 & 0,98 & 1,31 \\
\hline Kamonyi & 0 & 0 & 0 \\
\hline Karongi & 1,66 & 0,33 & 1,96 \\
\hline Rutsiro & 8,64 & 7,13 & 12,22 \\
\hline Rubavu & 0 & 0,58 & 0,29 \\
\hline Nyabihu & 3,92 & 6,7 & 7,05 \\
\hline Ngororero & 0 & 4,2 & 1,94 \\
\hline Rusizi & 17,91 & 21,66 & 28,42 \\
\hline Nyamasheke & 4,57 & 15,46 & 12,37 \\
\hline Rulindo & 0,75 & 1,47 & 1,47 \\
\hline Gakenke & 0 & 1,81 & 0,91 \\
\hline Musanze & 3 & 7,96 & 7,08 \\
\hline Burera & 16,45 & 47,6 & 40,02 \\
\hline Gicumbi & 2,65 & 8,4 & 6,83 \\
\hline Rwamagana & 0 & 18,83 & 9,60 \\
\hline Nyagatare & 1,57 & 57,07 & 30,04 \\
\hline Gatsibo & 0 & 10,35 & 5,18 \\
\hline Kayonza & 0 & 1,13 & 0,76 \\
\hline Kirehe & 35,25 & 16,89 & 42,40 \\
\hline Ngoma & 10,98 & 2,13 & 11,72 \\
\hline Bugesera & 0 & 1,28 & 0,64 \\
\hline
\end{tabular}

some districts, have zero or very low numbers of $S$. mansoni cases per year. Visually, there also are districts with high rates (respectively Nyagatare, Kirehe, Ngoma, Rusizi, and Burera); districts with zero rates (10 Districts in 2007 and only 2 in 2008) and districts with very low incidence rates. At HFSA level, the spatial pattern of $S$. mansoni is much more distinct, showing considerable differences within a district.

\section{Spatial autocorrelation of S. mansoni rates}

The results of spatial autocorrelation of neighboring values aggregated at HFSA and district level are summarized in Table 2.
The results were statistically significant at the district level and strongly significant at HFSA level $(p<0.05$ and z-score greater than 1.96). The statistically significant values indicate that the distribution $S$. mansoni is spatially heterogeneous in Rwanda and that heterogeneity is more explicit at HFSA level.

\section{Measures of spatial clustering (hotspots) of S. mansoni rates}

The identified statistically significant hotspot areas from the Local $\mathrm{Gi}^{*}$ (d) test of $S$. mansoni rates for the year 2007 and 2008 are visualized in Fig. 4.

The outcomes from spatial clustering analysis computed with Local $G i^{*}(d)$ statistic at district and HFSA levels are categorized as clusters ( $\mathrm{z}$-score $\geq 1.96$ ) or non-clusters (z-scores $<1.96)$, at different significance level.

\section{S. mansoni Spatial distribution in relation to environmental factors \\ Some risk factors have a significant relationship with $S$.} mansoni incidence. The sand percentage (of the soil) and elevation are negatively correlated with $S$. mansoni incidence rates, while ln-terrain shape index (TSI), temperature, rain, and rice cropped area in wetlands is positively correlated (see Table 3). Using R-squared and Standard error of the estimate, the risk factors included in the empirical model explain quite a lot regarding the spatial distribution of $S$. mansoni with a distinct effect of spatial scale. More than $47 \%$ of the distribution (with $\mathrm{S}$ of 0.926) at detailed HFSA level and 60\% (with S of 0.366) at the larger District level.

None of the two models included socio-hygienic variables such as educational attainment, the source of water or sanitation conditions. Even with the univariate test by Pearson's rank correlation (not reported here), none of the hygienic and socio-demographic factors had a significant association with S. mansoni incidence.

\section{Discussion}

This study identifies and visualizes the spatial variability of $S$. mansoni at two levels of spatial resolution using routinely collected health records as a basis. The incidence rates generated at HFSA levels were EBS smoothed, and the global mean was able to assign new rates, as recommended for disease mapping at a high spatial resolution [42] and in line with the considerable geographic concentration of S. mansoni in Rwanda [4] . The strong correlation between neighboring values at small scale was supported by the Global Moran's index. The spatial clustering test using Local $G_{i}^{*}(d)$ statistic also shows the non-random spatial distribution of $S$. mansoni. 


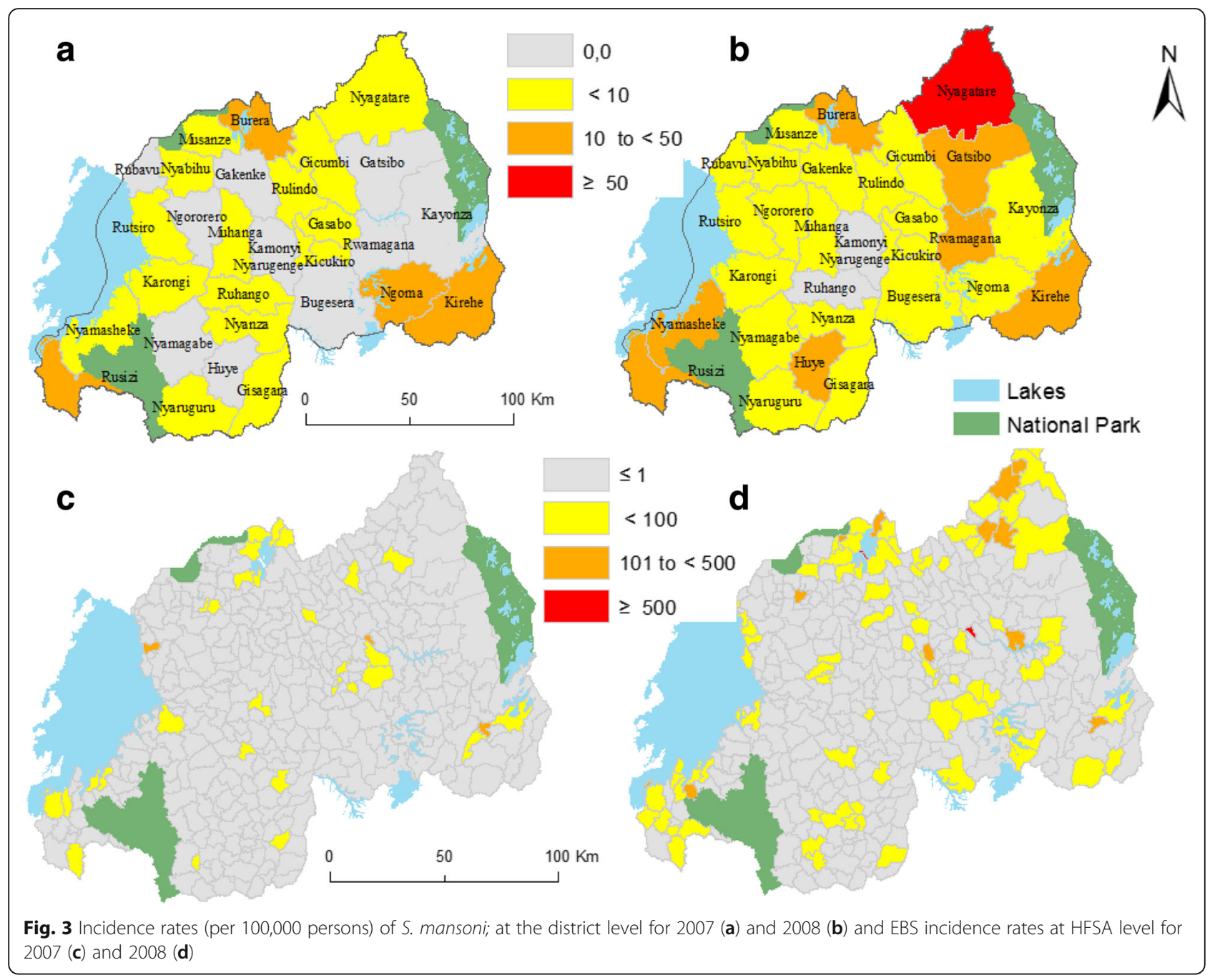

Routine health records provide valuable information for spatial pattern detection of S. mansoni

Disease maps depicting the spatial pattern of $S$. mansoni are essential for guiding control program activities. However, the added value of disease maps much depends on their spatial resolution, and on the underlying data used to establish them [43]. In this section, we first compare the incidence rates based maps at district and HFSA levels. The second comparison is between

Table 2 Test of spatial autocorrelation of S. mansoni rates computed for cumulative incidence (2007-2008) and the particular years (2007 and 2008)

\begin{tabular}{llllll}
\hline Year & District level & & & HFSA level & \\
\cline { 2 - 3 } & Moran'l $(p$ value $)$ & $Z(I)$ & & Moran'l $(p$ value $)$ & $Z$ Z (I) \\
\hline $2007-2008$ & $0.13(<0.001)$ & 5.03 & & $0.14(<0.001)$ & 5.03 \\
2007 & $0.24(0.05)$ & 1.89 & & $0,12(<0.001)$ & 4.36 \\
2008 & $0.12(0.29)$ & 1.10 & & $0.11(<0.001)$ & 3.65 \\
\hline
\end{tabular}

incidence rates based mapping and prevalence based mapping.

Figure 5 illustrates how spatial scale influences the detection of disease hotspots. The center map of Fig. 5 depicts incidence rates at the district level for 2007-2008, while the four smaller maps show the same information but now at the HFSA level. The HFSA level maps clearly show the highly focalized nature of $S$. mansoni hotspots. Representation at the district level, on the other hand, results in an overestimation of areas of high transmission as well as in non-identification of hotspots in districts with generally low incidence rates. The four identified hotspots areas at HFSA level (see Fig. 5) have also been identified by previous studies. The first and second hotspot areas are historically endemic zones of $S$. mansoni. Recently, Ruberanziza et al. [4] reported Nkombo Island (hotspot 1), as the most important $S$. mansoni focus in Rwanda. Ntaruka HFSA (hotspot 2) between Burera and Ruhondo lakes, was previously also identified as a high transmission area by several cross- 


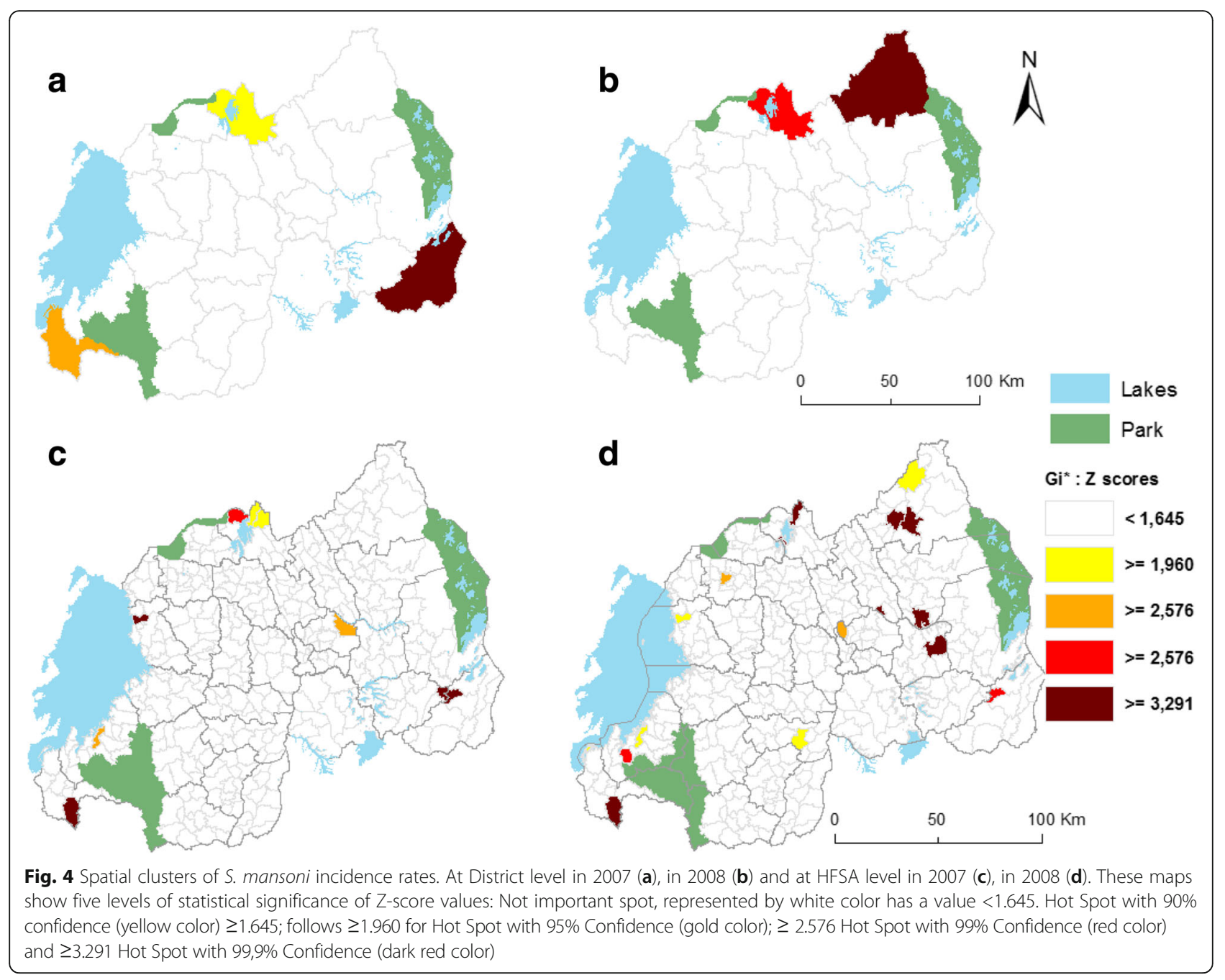

Table 3 Multiple regression outputs for the relationship between environmental factors and S. mansoni at HFSA and District level

\begin{tabular}{|c|c|c|c|c|c|}
\hline Parameters & B Coeff. & Standard Error & Beta Coeff. & t-value & $p$-value \\
\hline \multicolumn{6}{|l|}{ HFSA level model } \\
\hline Intercept & -0.697 & 0.238 & - & -2.931 & 0.004 \\
\hline Sand percentage & -0.004 & 0.001 & -0.366 & -3.816 & 0.000 \\
\hline Rice cropped area & 0.001 & 0.000 & 0.256 & 2.692 & 0.009 \\
\hline $\log -\mathrm{TS} \mid$ & 0.131 & 0.041 & 0.298 & 3.187 & 0.002 \\
\hline Rain & 0.001 & 0.000 & 0.281 & 2.585 & 0.012 \\
\hline Temperature & 0.028 & 0.010 & 0.296 & 2.832 & 0.006 \\
\hline \multicolumn{6}{|l|}{ District level model } \\
\hline Intercept & 1.999 & 0.906 & - & 2.207 & 0.036 \\
\hline Sand percentage & -0.032 & 0.010 & -0.447 & -3.216 & 0.003 \\
\hline Elevation & -0.002 & 0.000 & -0.661 & -4.373 & 0.000 \\
\hline Rain & 0.002 & 0.000 & 0.657 & 4.336 & 0.000 \\
\hline
\end{tabular}




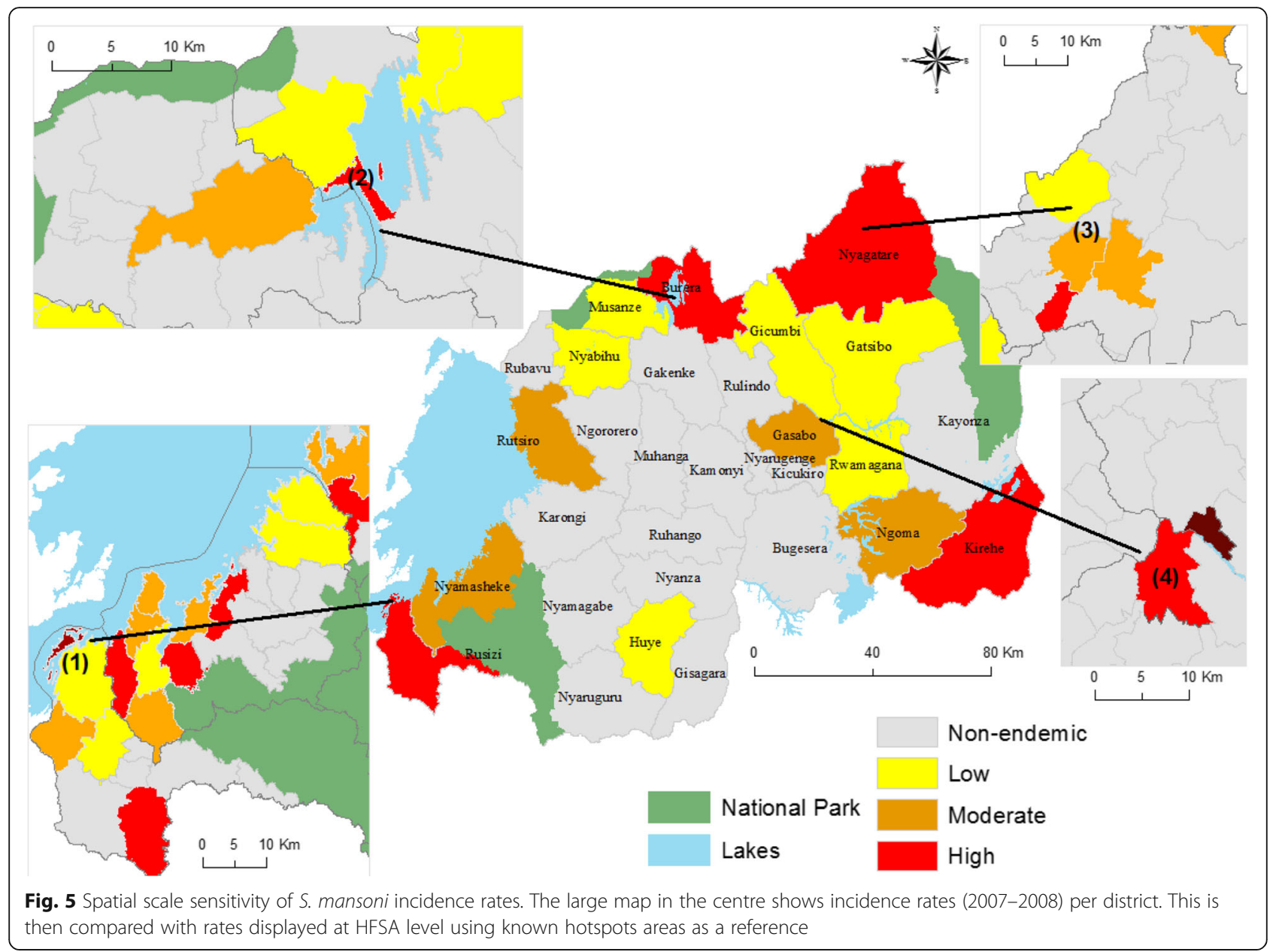

sectional surveys [5, 44, 45]. Hotspot 3 in Nyagatare and hotspot 4 in Gasabo district have not been documented before.

The second comparison, illustrated in Fig. 6, is at district level between the incidence-based map and two prevalence-based maps. The first (see Fig. 6a) is the prevalence map of 2008 published by WHO in 2010 [46]. The WHO map was produced using United Nations population data and prevalence estimations based on the procedure developed by Chitsulo et al. [21]. If we compare the WHO map with the one based on incidence data (Fig. 6b) there are obvious similarities, but with a notable exception for the Gicumbi district (red unit in Fig. 6a). According to the WHO mapping, Gicumbi district is hyper-endemic while in reality, the nationwide school-based prevalence survey (see Fig. 6c) identified three out of four sampled schools to be non-endemic (with a prevalence of $0 \%$ ).

In order to obtain a reliable disease burden measure, a prevalence survey is always needed. But the use of incidence data is suitable to identify high-resolution spatial patterns of disease distribution at the national scale. Disease maps based upon incidence data might also be used to guide a spatially explicit sampling procedure for improved prevalence sampling. This is important given that the spatial representability of surveyed schools is not well elaborated in current WHO guidelines for the evaluation of helminthiasis at the community level [47]. In some case, the cross-sectional survey was influenced by accessibility by four-wheel drive car [48]. Inaccessible areas with poor quality or non-existent roads around valleys and perennial water bodies are usually poorly represented in school samples obtained, while those have now been identified as potential high-risk areas [49].

\section{S. mansoni Incidence rates and environmental risk factors}

This study detected a significant relationship between $S$. mansoni incidence rates and potential environmental risk factors as summarized in Table 3. Elevation and sand percentage in the soil are negatively correlated with $S$. mansoni incidence, whereas temperature, rainfall, and wetlands used for rice cultivation are positively associated. These findings are consistent with existing knowledge on the environmental conditions required for the 


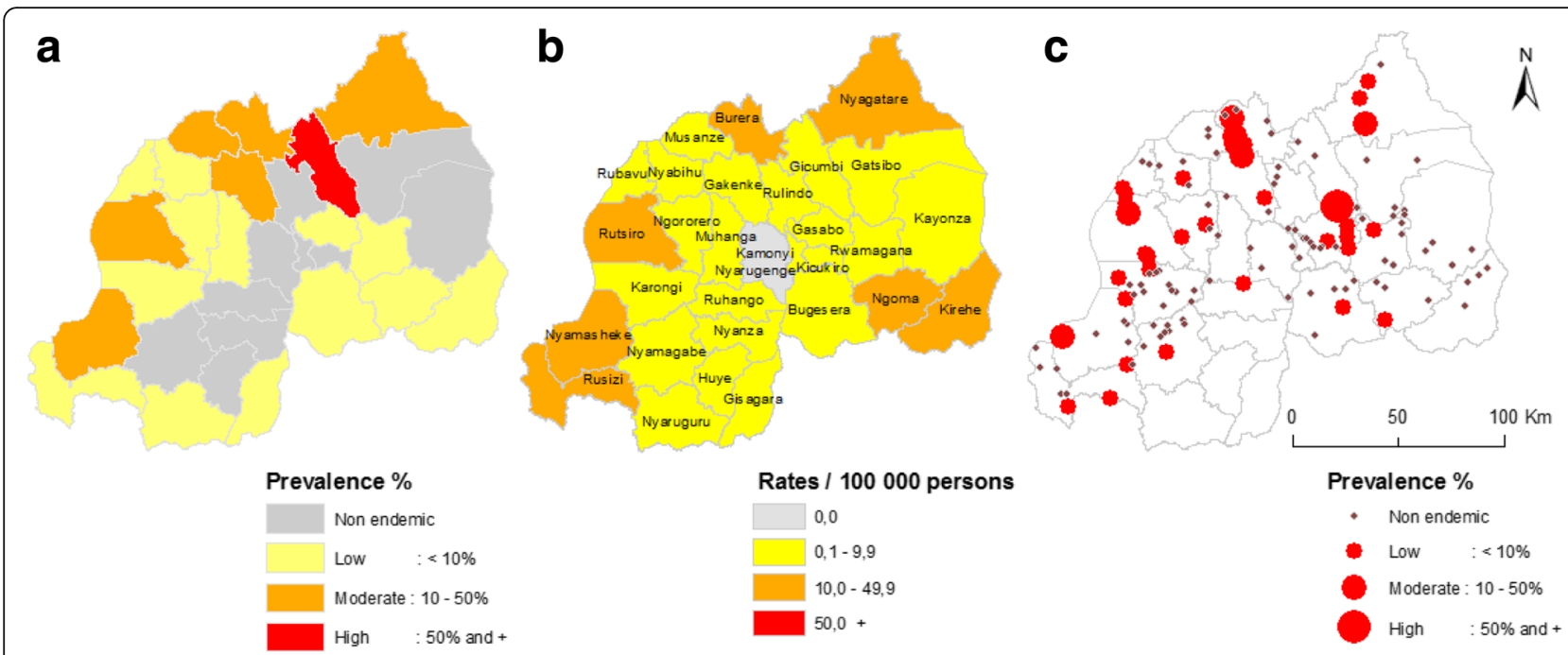

Fig. 6 The spatial pattern of S. mansoni at the district level. The first prevalence map of 2008 was produced by WHO using global data and spatial simulation (a); the center map shows the cumulative incidence rates (2007-2008) at the district level to allow comparison (b) and the school-based prevalence survey of 2007-2008 (c)

development of the intermediate host snails and hence, can influence transmission risk. The related physical and ecological parameters were similar to other studies $[1,50,51]$. Low elevation, valley wetlands, warm and humid conditions and less sandy soil create favorable conditions for S. mansoni, as host snails inhabit places with lower altitudes and wetlands with natural or cultivated vegetation $[50,52]$. The TSI offer additional and important information for discriminating the implications of those changes on wetness conditions more than soil types do [53].

Prior research has demonstrated that S. mansoni infection can increase as a result of the construction of dams or irrigation schemes [54]. Indeed, within irrigation systems transmission is focal and primarily due to localized contamination of habitats with human excreta containing Schistosoma eggs [55]. The newly identified hotspot in Nyagatare district (hotspot 3 in Fig. 5) is close to a more than 1000 ha irrigation scheme for rice cropping. Furthermore, intense cultivation such as flowers and sugarcane within Nyabarongo wetland can be linked with the hotspot identified in Kigali city (see hotspot 4 in Fig. 5). A similar situation was also reported for Minas Gerais State in Brazil [56]. This indicates that vulnerability to $S$. mansoni is not limited to rural populations, school children or women of childbearing age but extends to entire communities.

\section{Limitations of this research approach}

Although the incidence data from routine health records have a high quality as described in the methodology section, the number of confirmed cases will still only be a fraction of all infected persons and will mostly concern patients manifesting clinical symptoms. If the incidence database could be enriched with additional information (e.g. intensity of infection in tested stools, the total number of investigated subjects and their age and sex) the outcomes of the analysis would become even more robust.

Regarding the patterns analysis and clusters mapping, we used the Global Moran's I and Local Gi* (d) statistic instead of local Moran's I. However, both statistical tests are related; the correlations between nearby values of the statistics are derived and verified by simulation. In this specific case, with aggregated values at HFSA level, the spatial autocorrelation was weak (Moran's I is not closer to +1 ) and statistically significant hot spots, cold spots, and spatial outliers were only distinguished with Local Gi* (d) statistics. Thus, the linear regression, although not the best approach for the spatially autocorrelated dataset, presented satisfactory results for exploratory analysis of disease risk factors. Given that there was no strong spatial dependency between closer values (as proven by semi variogram test). Additionally, the risk for a fixed spatial pattern was prevented by sampling randomly the model calibration data subset.

Somewhat unexpected is that none of the demographic and socio-economic variables had a significant contribution to explaining $S$. mansoni incidence variability at HFSA level. A plausible explanation for this is that in Rwanda there is low variability in levels of school attendance, access to improved water sources, proper sanitation, and wearing of shoes [16, 17]. In Rwanda, conditions have much improved as a result of significant policy achievements in the last two decades $[57,58]$. Consequently, additional information about people's behavior would be required to further improve 
our understanding of S. mansoni risk factors. Possible examples are the habit of taking off shoes while working in the field, defecation in bushes when working on the land (and thus far from the home toilet), which may be important to better understand $S$. mansoni exposure $[1,9,59]$.

The multiple regression models explain a lot of the observed spatial variability of $S$. mansoni incidence rates as a function of possible locational risk factors. The district model performed better than the model at the more detailed HFSA level. This is consistent with the fact that aggregation of data causes linearization contributing to overestimation in linear regressions [60].

\section{Conclusion}

This study has demonstrated that in Rwanda prevalence and incidence data for S. mansoni are highly correlated. Given the availability of reported cases for each health facility in Rwanda, a high resolution spatially explicit statistical investigation of $S$. mansoni hotspots is feasible. The identified risk areas provide an appropriate basis to guide S. mansoni control programs at a much more detailed spatial scale than was possible before. In addition, the most important physical, ecological and climatic risk factors for S. mansoni transmission in Rwanda were identified. It was also shown that intensive agricultural use and transformation of wetlands for rice cultivation contributes to the spreading of $S$. mansoni into previously non-endemic areas. In line with environmental health impact monitoring and evaluation for wetland based development projects, a specific policy is required to address and reduce potential disease risk associated with rural development efforts. Finally, use of routinely collected incidence data opens the door for spatiotemporal analysis of $S$. mansoni and environmental risk factors which will vary in space and time.

\section{Acknowledgements}

The authors are thankful to Noella Umulisa, Alain Kabayiza, Alphonse Rukundo and Alphonse Mutabazi, staff members of the Malaria and Other Parasitic Diseases Division of the Rwanda Biomedical Centre. We extend our sincere appreciation to the Rwandan Meteorological Center, Rwanda Natural Resources Authority/Land and Mapping Department, Rwanda Environment Management Authority and the Geographic Information Systems and Remote Sensing Centre of University of Rwanda (CGIS-UR) for providing environmental risk factors readily pre-processed for this study.

\section{Funding}

This study was financially supported by the Dutch Government, Nuffic Programme under the NICHE/RWA/071 project. The project had no role in the study design, data collection, analysis, interpretation, or manuscript writing.

\section{Availability of data and materials}

The datasets generated and/or analyzed during the current study are not publicly available due to the agreement on data sharing signed between the researcher and the Rwanda Biomedical Centre, Division of Malaria and Others Parasitic Disease (RBC/M\&OPD) but are available from the corresponding author upon request.

\section{Authors' contributions}

$E N, A V, C K, I U$ and SA participated in the design of the study and in outlining the manuscript. EN organized and analyzed the data, interpreted the results and reviewed the literature under the supervision of AV and SA. CK and IU substantially contributed to acquisition of data and their interpretation. All authors have been involved in drafting the manuscript and have read and approved the manuscript before submission.

Ethics approval and consent to participate

Not applicable. The routinely recorded statistics of confirmed cases from the Rwandan Health Management Information System (R-HMIS) are collected without personal information.

\section{Consent for publication}

Not applicable.

\section{Competing interests}

The authors declare that they have no competing interests.

\section{Publisher's Note}

Springer Nature remains neutral with regard to jurisdictional claims in published maps and institutional affiliations.

\section{Author details}

${ }^{1}$ Faculty of Geo-Information Science and Earth Observation (ITC), University of Twente, P. O. Box 217, 7500 AE Enschede, the Netherlands. ${ }^{2}$ Geographic Information Systems and Remote Sensing Centre of University of Rwanda, P.O Box 212, Huye, Rwanda. ${ }^{3}$ Rwanda Biomedical Centre/ Malaria and Other Parasitic Diseases Division, P. O. Box 2514, Kigali, Rwanda. ${ }^{4}$ Swiss Tropical and Public Health Institute, Socinstrasse 57, P.O. Box, CH-4002 Basel, Switzerland.

${ }^{5}$ Universität Basel, Petersplatz 1, CH-4003 Basel, Switzerland.

Received: 9 June 2016 Accepted: 3 October 2017

Published online: 25 October 2017

\section{References}

1. Schur N, Hurlimann E, Stensgaard A-S, Chimfwembe K, Mushinge G, Simoonga $C$, et al. Spatially explicit Schistosoma infection risk in eastern Africa using Bayesian geostatistical modeling. Acta Trop. 2013;128(2013):365-77.

2. Sacko M, Magnussen P, Keita AD, Traoré MS, Landouré A, Doucouré A et al. Impact of Schistosoma haematobium infection on urinary tract pathology, nutritional status and anaemia in school-aged children in two different endemic areas of the Niger River basin, Mali. Acta Tropica. 2011;120, Supplement 1(0):S142-S50 doi:101016/jactatropica201012.009.

3. WHO. Preventive chemotherapy in human helminthiasis: coordinated use of anthelminthic drugs in control interventions : a manual for health professionals and program managers. Geneva: World Health Organization; 2006.

4. Ruberanziza E, Kabera M, Ortu G, Kanobana K, Mupfasoni D, Ruxin J, et al. Nkombo Island: the most important Schistosomiasis mansoni focus in Rwanda. Am J of Life Sci. 2015;3(1):27-31. doi:10.11648/j.ajls.20150301.16.

5. Ruberanziza E, Mupfasoni D, Karibushi B, Kabera M, Karema C, Nyatanyi T et al. A Recent Update of Schistosomiasis Mansoni Endemicity Around Lake Rweru. Rwanda Medical Journal/Revue Médicale Rwandaise. 2010;68(4).

6. Isabwe A, Ruberanziza E, Mupfasoni D, Ruxin J, Clerinx J, White P. Potential for transmission of Schistosomiasis in Kayonza District Rwanda medical. Journal. 2012:69(2):14-9.

7. Standley CJ, Adriko M, Alinaitwe M, Kazibwe F, Kabatereine NB, Stothard JR. Intestinal schistosomiasis and soil-transmitted helminthiasis in Ugandan schoolchildren: a rapid mapping assessment. Geospat Health. 2009:4(1):39-53.

8. Meurs L, Mbow M, Boon N, van den Broeck F, Vereecken K, Dièye TN, et al. Micro-geographical heterogeneity in Schistosoma Mansoni and S. Haematobium infection and morbidity in a co-endemic Community in Northern Senegal. PLoS Negl Trop Dis. 2013;7(12):e2608. doi:10.1371/journal. pntd.0002608.

9. Congdon PA. Multilevel model for cardiovascular disease prevalence in the US and its application to micro area prevalence estimates. Int J Health Geogr. 2009;8(1):1-14. doi:10.1186/1476-072X-8-6. 
10. Odoi A, Martin SW, Michel P, Holt J, Middleton D, Wilson J. Geographical and temporal distribution of human giardiasis in Ontario. Canada Int Health Geogr. 2003;2(1):5. doi:10.1186/1476-072x-2-5.

11. Osei F, Duker A. Spatial and demographic patterns of cholera in Ashanti region - Ghana. Int J Health Geogr. 2008;7(1):44.

12. Vega-Corredor MC, Opadeyi J. Hydrology and public health: linking human leptospirosis and local hydrological dynamics in Trinidad, West Indies. Earth. Perspectives. 2014;1(1):1-14. doi:10.1186/2194-6434-1-3.

13. Hu Y, Zhang Z, Chen Y, Wang Z, Gao J, Tao B, et al. Spatial pattern of schistosomiasis in Xingzi, Jiangxi Province, China: the effects of environmental factors. Parasit Vectors. 2013;6(1):214.

14. Utzinger J, Raso G, Brooker S, De Savigny D, Tanner M, ØRnbjerg N, et al. Schistosomiasis and neglected tropical diseases: towards integrated and sustainable control and a word of caution. Parasitology. 2009;136(13):185974. doi:10.1017/S0031182009991600.

15. Steinmann P, Keiser J, Bos R, Tanner M, Utzinger J. Schistosomiasis and water resources development: systematic review, meta-analysis, and estimates of people at risk. Lancet Infect Dis. 2006;6(7):411-25. doi:10.1016/ s1473-3099(06)70521-7.

16. Rollemberg CV, Silva MM, Rollemberg KC, Amorim FR, Lessa NM, Santos MD, et al. Predicting frequency distribution and influence of sociodemographic and behavioral risk factors of Schistosoma Mansoni infection and analysis of co-infection with intestinal parasites. Geospat Health. 2015;10(1):303. doi:10. 4081/gh.2015.303

17. Schmidlin T, Hürlimann E, Silué KD, Yapi RB, Houngbedji C, Kouadio BA, et al. Effects of hygiene and defecation behavior on Helminths and intestinal protozoa infections in Taabo, Côte d'Ivoire. PLoS One. 2013;8(6):e65722. doi: 10.1371/journal.pone.0065722.

18. Ro R. Organic law no $29 / 2005$ of $31 / 12 / 2005$ determining the administrative entities of the Republic of Rwanda. 31/10/2005 ed. Kigali: Official Gazette of the Republic Rwanda; 2005

19. NISR. Fourth Rwanda Population and Housing Census. Thematic Report: Population Projections. January 2014 ed. Kigali2014.

20. Nabahungu NL. Problems and opportunities of wetland management in Rwanda. Wageningen: Wageningen University; 2012.

21. Chitsulo L, Engels D, Montresor A, Savioli L. The global status of schistosomiasis and its control. Acta Trop. 2000;77(1):41-51. doi:http://dx.doi.org/10.1016/S0001706X(00)00122-4.

22. USAID/Rwanda. Rwanda HMIS assessment report. Kigali Ministry of Health GoR. 2006 May;9:2006.

23. Walz Y, Wegmann M, Dech S, Raso G, Utzinger J. Risk profiling of schistosomiasis using remote sensing: approaches, challenges and outlook Parasit Vectors. 2015;8:163. doi:10.1186/s13071-015-0732-6.

24. Nyandwi E, Veldkamp TA, Amer S. Regional climate sensitivity of wetland environments in Rwanda: the need for a location-specific approach. Reg Environ Chang. 2015;15(8) doi:10.1007/s10113-015-0905-z.

25. Verdoodt A, Van Ranst E. Environmental assessment tools for multi-scale land resources information systems: a case study of Rwanda. Agric Ecosyst Environ 2006;114(2-4):170-84. doi:http://dx.doi.org/10.1016/j.agee.2005.10.006.

26. Tsai P-J, Lin M-L, Chu C-M, Perng C-H. Spatial autocorrelation analysis of health care hotspots in Taiwan in 2006. BMC Public Health. 2009;9(1):1-13. doi:10.1186/1471-2458-9-464

27. Osei F. Current statistical methods for spatial epidemiology: a review. Austin Biometrics and Biostatistics. 2014;1(2)

28. Rothman KJ. Epidemiology: an introduction. 2nd edition ed. Oxford: Oxford University Press, Inc.; 2012.

29. Goovaerts P. Accounting for rate instability and spatial patterns in the boundary analysis of cancer mortality maps. Environ Ecol Stat. 2008;15(4): 421-46. https://doi.org/10.1007/s10651-007-0064-6.

30. CDC. BioMedware SpaceStat- Empirical Bayesian Smoothing. 2014. Accessed November, 5th 20142014.

31. Boots B, Getis A. Point pattern analysis. Newbury Park, CA: Sage Publications; 1998.

32. Cliff A, Ord J. Spatial autocorrelation. London: Pion Limited; 1973.

33. Anselin L. The local indicators of spatial association - LISA. Geogr Anal. 1995; 27:93-115. doi:10.1111/j.1538-4632.1995.tb00338.x

34. Getis A, Ord JK. The analysis of spatial association by use of distance statistics. Geogr Anal. 1992;24(3):189-206. doi:10.1111/j.1538-4632.1992.tb00261.x.

35. Ord JK, Getis A. Local spatial autocorrelation statistics: distributional issues and an application. Geogr Anal. 1995;27(4):286-306. doi:10.1111/j.1538-4632. 1995.tb00912.x.
36. Wu J, Wang J, Meng B, Chen G, Pang L, Song X, et al. Exploratory spatial data analysis for the identification of risk factors to birth defects. BMC Public Health. 2004:4:23. doi:10.1186/1471-2458-4-23.

37. Ceccato V, Persson LO. Dynamics of rural areas: an assessment of clusters of employment in Sweden. J Rural Stud. 2002;18(1):49-63. doi:http://dx.doi.org/ 10.1016/S0743-0167(01)00028-6.

38. Limpert E, Stahel WA, Abbt M. Log-normal distributions across the sciences: keys and clues. Bioscience. 2001;51(5)

39. Lemeshow S, Moeschberger ML. Review of regression methods in biostatistics: linear, logistic, survival, and repeated measures models by Vittinghoff, Glidden, Shiboski, and McCulloch. The Strata. 2005;5(2):274-8.

40. Kabo GJ, Paulechka YU, Zaitsau DH, Firaha AS. Prediction of the enthalpies of vaporization for room-temperature ionic liquids: correlations and a substitution-based additive scheme. Thermochim Acta. 2015:609:7-19. doi: http://dx.doi.org/10.1016/j.tca.2015.04.013

41. Wang ZJ, Chapiro J, Schernthaner R, Duran R, Chen RX, Geschwind JF, et al. Multimodality 3D tumor segmentation in HCC patients treated with TACE. Acad Radiol. 2015;22(7):840-5. doi:10.1016/j.acra.2015.03.001.

42. Bithell JFA. Classification of disease mapping methods. Stat Med. 2000; 19(17-18):2203-15.

43. Moore DA, Carpenter TE. Spatial analytical methods and geographic information systems: use in Health Research and epidemiology. Epidemiol Rev. 1999;21(2) doi:10.1093/oxfordjournals.epirev.a017993.

44. Hanotier J, Gigase PL. Note on a new focus of schistosomiasis (S. Mansoni) in Rwanda. Annales de la Societe belge de medecine tropicale. 1981;61(1):93-8.

45. Mupfasoni D, Karibushi B, Koukounari A, Ruberanziza E, Kaberuka T, Kramer $\mathrm{MH}$ et al. Polyparasite Helminth infections and their association to Anaemia and Undernutrition in northern Rwanda. 2009.

46. WHO. Rwanda - Country Profile. Preventive Chemotherapy and Transmission Control. Department of Control of Neglected Tropical Diseases, Geneva/ Switzerland: WHO, Diseases DoCoNT;2010.

47. Montresor A, Crompton DWT, Hall A, Bundy DAP, Savioli L. Guidelines for Evaluation of Soil-Transmitted Helminthiasis and Schistosomiasis at Community Level. Geneva: WHO1998 Contract No: WHO/CTD/SIP/98.1.

48. Assare RK, Lai YS, Yapi A, Tian-Bi YN, Ouattara M, Yao PK, et al. The spatial distribution of Schistosoma Mansoni infection in four regions of western cote d'Ivoire. Geospat Health. 2015;10(1):345. doi:10.4081/gh. 2015.345

49. Simoonga C, Kazembe LN, Kristensen TK, Olsen A, Appleton CC, Mubita P, et al. The epidemiology and small-scale spatial heterogeneity of urinary schistosomiasis in Lusaka province, Zambia. Geospat Health. 2008;3(1):57-67. doi:10.4081/gh.2008.232.

50. Alemayehu B, Tomass Z. Schistosoma Mansoni infection prevalence and associated risk factors among schoolchildren in Demba Girara, Damot Woide District of Wolaita zone, southern Ethiopia. Asian Pac J Trop Med. 2015;8(6):457-63. doi:http://dx.doi.org/10.1016/j.apjtm.2015.05.009.

51. Fonseca F, Freitas C, Dutra L, Guimarães R, Carvalho O. Spatia modeling of the schistosomiasis mansoni in Minas Gerais state, Brazil using spatial regression. Acta Trop. 2014;133(0):56-63. doi:http://dx.doi. org/10.1016/j.actatropica.2014.01.015.

52. Bavia ME, Hale LF, Malone JB, Braud DH, Shane SM. Geographic information systems and the environmental risk of schistosomiasis in Bahia, Brazil. Am J Trop Med Hyg. 1999:60:566-72.

53. Fontaine M, Aerts R, Özkan K, Mert A, Gülsoy S, Süel H, et al. Elevation and exposition rather than soil types determine communities and site suitability in Mediterranean mountain forests of southern Anatolia, Turkey. For Ecol Manag. 2007;247(1-3):18-25. doi:http://dx.doi.org/10.1016/j.foreco.2007.04.021.

54. Steinmann P, Keiser J, Bos R, Tanner M, Utzinger J. Schistosomiasis and water resources development: systematic review, meta-analysis, and estimates of people at risk. Lancet Infect Dis. 2006;6(7):411-25. doi:10.1016/ S1473-3099(06)70521-7.

55. Boelee E. Irrigation ecology of schistosomiasis : environmental control options in Morocco. Wageningen: Wageningen University; 2000.

56. Guimarães RJPS, Freitas CC, Dutra LV, Moura ACM, Amaral RS, Drummond SC, et al. Schistosomiasis risk estimation in Minas Gerais state, Brazil, using environmental data and GIS techniques. Acta Trop. 2008;108(2-3):234-41. doi:http://dx.doi.org/10.1016/j.actatropica.2008.07.001

57. Rwanda Ro. Demographic and Health Survey [DHS] 2014/2015. Key findings. In: (NISR) NIOSoR, editor. Kigali2015. 
58. United Nations. Millenium declaration 2000.

59. Brooker S, Kabatereine NB, Smith JL, Mupfasoni D, Mwanje MT, Ndayishimiye $\mathrm{O}$, et al. An updated atlas of human helminth infections: the example of East Africa. Int J Health Geogr. 2009; doi:10.1186/1476-072X-8-42.

60. Kok K, Veldkamp T. Scale and governance: conceptual considerations and practical implications. Ecol Soc. 2011;16(2)

Submit your next manuscript to BioMed Central and we will help you at every step:

- We accept pre-submission inquiries

- Our selector tool helps you to find the most relevant journal

- We provide round the clock customer support

- Convenient online submission

- Thorough peer review

- Inclusion in PubMed and all major indexing services

- Maximum visibility for your research

Submit your manuscript at www.biomedcentral.com/submit 